\title{
The Analysis of Dissimilar Metal Weld Joints
}

\author{
Vijay Ramachandhar CHINNAPPASHANMUGAM*, Jolanta BASKUTIENE**, \\ Saulius BASKUTIS***, Evaldas NARVYDAS****, Kestutis VAITASIUS****** \\ *Kaunas University of Technology, Studentu st. 56, LT-51424 Kaunas, Lithuania, \\ E-mail: vijayrama-chandhar.chinnappa@ktu.edu \\ **Kaunas University of Technology, Studentu st. 56, LT-51424 Kaunas, Lithuania, E-mail: jolanta.baskutiene@ktu.lt \\ ***Kaunas University of Technology, Studentu st. 56, LT-51424 Kaunas, Lithuania, E-mail: saulius.baskutis@ktu.lt \\ ****Kaunas University of Technology, Studentu st. 56, LT-51424 Kaunas, Lithuania, E-mail: evaldas.narvydas@ktu.lt \\ *****Kaunas University of Technology, Studentu st. 56, LT-51424 Kaunas, Lithuania, E-mail: kestutis.vaitasius@ktu.lt \\ cross $^{\text {ref }}$ http://dx.doi.org/10.5755/j01.mech.24.2.20679
}

\section{Introduction}

The exhaust system of a motorcycle plays a major role in reducing the engine noise, removing waste gases from the engine and aiming to offer good serviceability, design, style and cost per the customer needs. Nowadays the additive manufacturing processes are widely used to make small quantities of structural and functional components such as engine exhausts, drive shafts and gearbox components $[1,2]$. The exhaust system of motorcycles of high-end models is 3D printed and have many advantages like design flexibility, corrosion resistance etc. The exhaust system of motorcycles of low-end models is fabricated by welding of different metals, including mild steel, stainless steel, ferritic steel, etc. Majority of modern motorcycles are fabricated using mild steel with zinc coating, ceramics or other kind of coating aiming to increase the corrosion resistance, however, these coatings offer corrosion resistance only for a certain period.

The materials, which are regularly used for the exhaust components of a motorcycle, are aluminized mild steel and a stainless steel. Corrosion is one of the major problems in mild steel, which eventually reduces the product lifetime. Due to aggressive environmental condition, even some stainless steels do not possess strong corrosion resistance [1]. The lifetime of the main fold is comparatively less when compared to the other parts of the exhaust system in the motorcycle. Steel grades AISI 409 and 439 have less thermal coefficient and can be used in the production of exhaust pipes, but the main disadvantage is that they are difficult to weld. Aluminised mild steel is another option for producing exhaust pipes but main problem is that these types of steel are prone to high temperature corrosion and heat resistant. The corrosion resistance of a mild steel, which is subjected to oxidation, may be improved by coating [3, 4]. The exhaust systems, which suffer from poor corrosion resistance, have relatively short life time. The corrosion resistance of mild steel may be eventually improved by zinc-nickel coating.

Therefore, considering a material for production of exhaust pipes and main fold in motorcycles the stainless steel of grade 304 could be considered, because this material is suitable for harsh and aggressive environmental conditions. Experimental analysis of the weld joint of this metal to A508Gr.3Cl.1 ferritic steel using Inconel 82/182 filler was presented in [5] with a reference to using it in a nuclear industry.
There is different type of defects that can occur in a welded joint due to various reasons and can cause unexpected failures. During the welding, when the filler material is not properly fused with the parent material, the lack of fusion occurs. This defect on the weld can causes incomplete fuse spots. The defect can occur on the side of the weld, in between the weld and on the bottom of the weld. This defect cannot be easily detected by visual inspection. But sometimes, using the non-destructive testing methods, these defects can be detected [6]. It takes a significant magnification to detect lack of fusion in between the weld through microscope [6]. A typical lack of fusion in the exhaust pipe due to unmelted oxide inclusions and non-metallic inclusions [7] is shown in the Fig. 1.

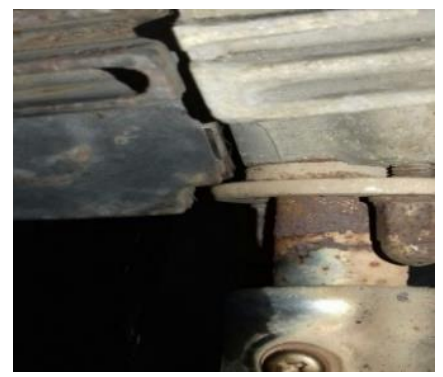

Fig. 1 Crack due to lack of fusion and visible result of corrosion

The paper aims to investigate the mechanical properties of the welded tubular specimen where AISI 304 and AISI 1018 steel was used as a main material.

\section{Experimental investigations}

\subsection{Preparation of the specimens}

The specimens for the analysis have been made of mild steel and stainless steel. A long round bars of mild steel and stainless steel have been cut into pieces of particular length and using the lathe machine it is reduced to smaller dimensions using turn operation. After fabricating it to proper dimension, the specimen was drilled to required diameter using a drill bit. The wall thickness of the specimen was $2.5 \mathrm{~mm}$ and outside diameter of the specimen was 20 mm of the tested part (Fig. 2). The specimen comprises two parts, which are made of stainless steel and mild steel and the butt weld. The total length of the specimen was $150 \mathrm{~mm}$. 
The specimens have been welded using different filler materials: 316L, 308L and E70-S2. The two parts of the specimen (Fig. 3, a) have been joined by welding (Fig. 3, b) by

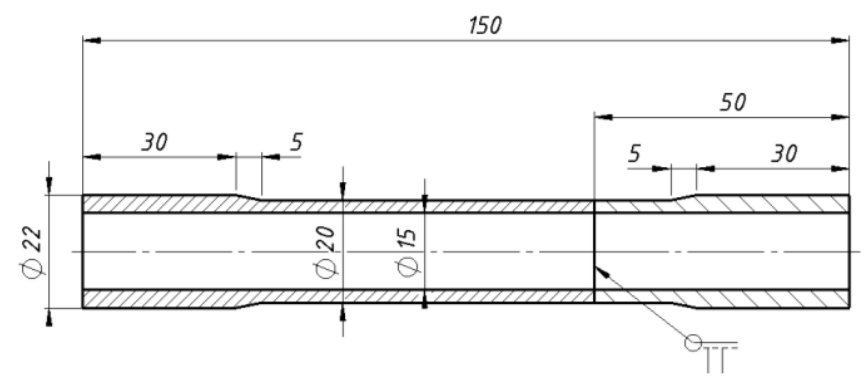

Fig. 2 Major dimensions of the specimen

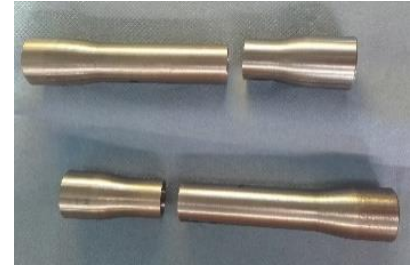

a

b

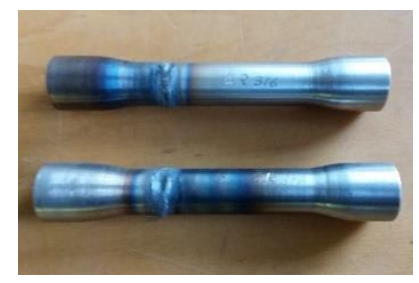

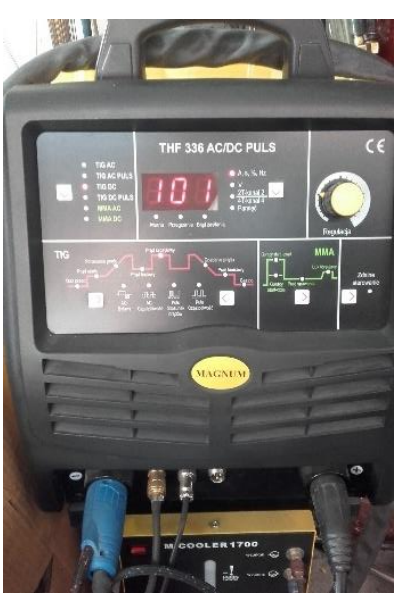

c
Fig. 3 Specimens prior to welding (a), specimens after the welding (b), and TIG welding machine used for welding (c)

Tungsten arc welding using the filler material and welding machine MAGNUM TIG THF 336 PULSE AC/DC (Fig. 3, c). The welding current was $101 \mathrm{~A}$ and voltage during welding was $16.5 \mathrm{~V}-17 \mathrm{~V}$ kept constant during the welding of the all specimens. The torch was maintained at an angle between 30 degrees and was guided towards the welding direction. The filler wire was fed at an angle of 60 degree to the base material. The filler material was kept close to the gas flow near the nozzle. The mild steel specimens have been welded using E70-S2 filler material, whereas stainless steel specimens have been welded using 308L filler material. The components made of mild steel and stainless steel have been joined by welding using $316 \mathrm{~L}$ filler material. In Fig. 3, b the specimens welded of stainless steel are presented. The properties of the main material and used filler materials are given in Table 1.

Table 1

Mechanical properties of main material and filler [8,9]

\begin{tabular}{|c|c|c|c|}
\hline Material & $\begin{array}{c}\text { Tensile } \\
\text { strength min., } \\
\mathrm{MPa}\end{array}$ & $\begin{array}{c}\text { Yield strength } \\
\text { min., MPa }\end{array}$ & $\begin{array}{c}\text { Elongation, } \\
\text { min. \% }\end{array}$ \\
\hline 304 & 515 & 205 & 40 \\
\hline 1018 & 440 & 370 & 15 \\
\hline E70-S2 & 516 & 441 & 24 \\
\hline 308L & 600 & 393 & 34 \\
\hline $316 \mathrm{~L}$ & 540 & 400 & 38 \\
\hline
\end{tabular}

\subsection{Tensile testing}

The tensile test has been used to determine the tensile strength of welded stainless steel and mild steel specimens. Fig. 4 shows the tension-compression machine along with the specimen fixed inside the gripper. The central part of the specimen is important. This part is called the gauge section and has the reduced cross-section area if compared to the ends of the specimen, which are used to grip the specimen [10]. The gauge length of the specimen was denoted to be able to define the elongation length after the test. The initial length and diameter were measured. The tensile strength of the stainless steel and mild steel is known. The test was conducted until the breaking point. After the test the neck of the specimen is measured as well as the length of the specimen. In Fig. 5, the specimen after the tensile test is shown.

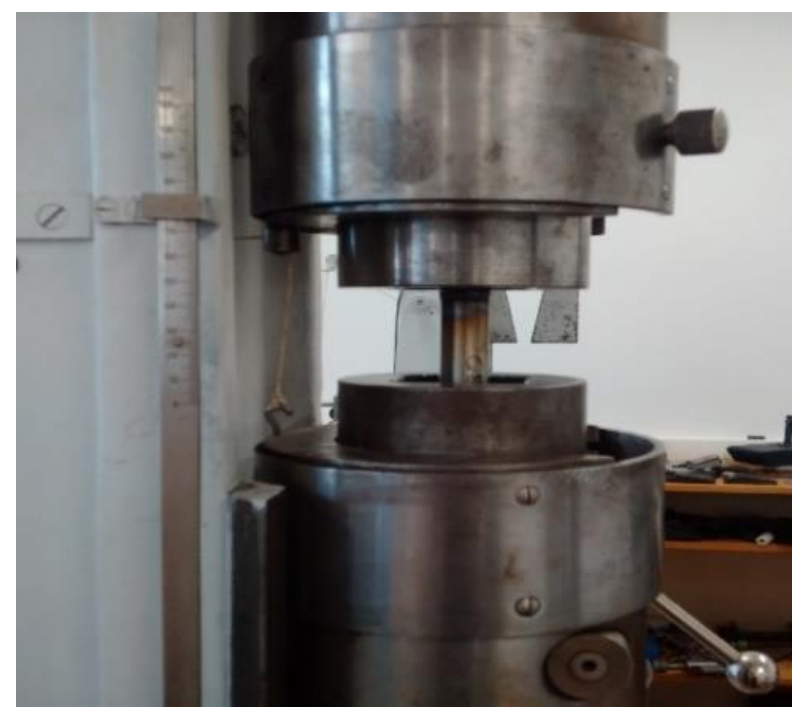

Fig. 4 The specimen fixed in the tension-compression testing machine

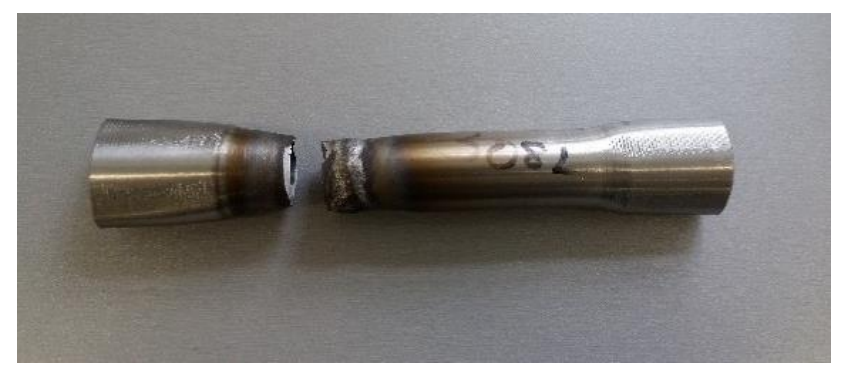

Fig. 5 Specimen after the tensile test

During the test, the load $(F)$ and displacement $(\Delta l)$ were measured and the test was conducted until the fracture. The readings were taken at intervals and used to construct the engineering $F-\Delta l$ curve shown in the Fig 6. Here, curve 1 represents specimen welded of stainless steel pars; 2 - low carbon (mild) steel pars and the curve 3 - the combination of stainless and mild steel. The maximal static load the welded specimen can carry out was determined. As it is seen from the Fig. 6, the maximum load of $87.5 \mathrm{kN}$ was for the specimens welded of AISI 304 steel with AISI 308L filler; load of $87.0 \mathrm{kN}$ was for the specimens welded of AISI 1018 steel with the filler E70-S2; and load of $85.0 \mathrm{kN}$ was for the combined specimens of 304 and 1018 steel with the 
weld of $316 \mathrm{~L}$ steel material. The results of maximum load are very similar and fit in to a range of $3 \%$ difference with an average of $86.5 \mathrm{kN}$.

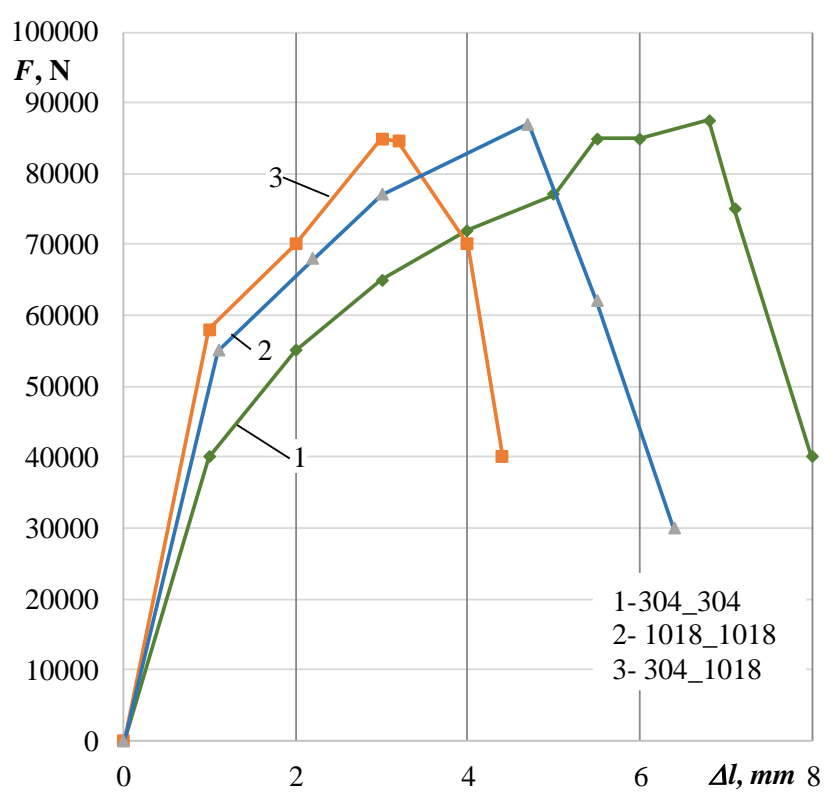

Fig. 6 Tension test diagram of welded specimens

\subsection{Vickers hardness tests}

Vickers hardness test was performed in addition to the tensile test to determine the welded zone with the changed hardness comparing with the main material. The force of $5 \mathrm{kgf}$ was applied for a $5 \mathrm{~s}$, that correspond to HV5/5 Vickers hardness units. The Fig. 7 shows the screen of the hardness test operation.

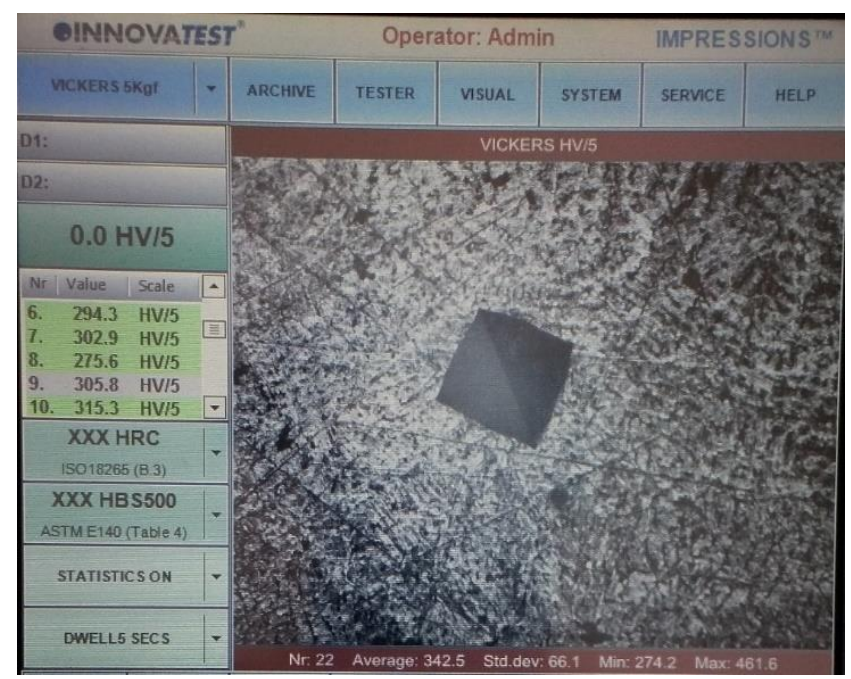

Fig. 7 Vickers hardness test result on the screen

The hardness test shows no significant difference in hardness between main material - steel 304 and the weld material - 308L or 316L (Fig. 8, series 304_304 and 304_1018). However, the hardness test of the specimen with the weld of steel E70-S2 allow to distinguish the region of main material (hardness about $300 \mathrm{HV} 5 / 5$ ) and the weld (hardness about 420 HV5/5, see Fig. 8).

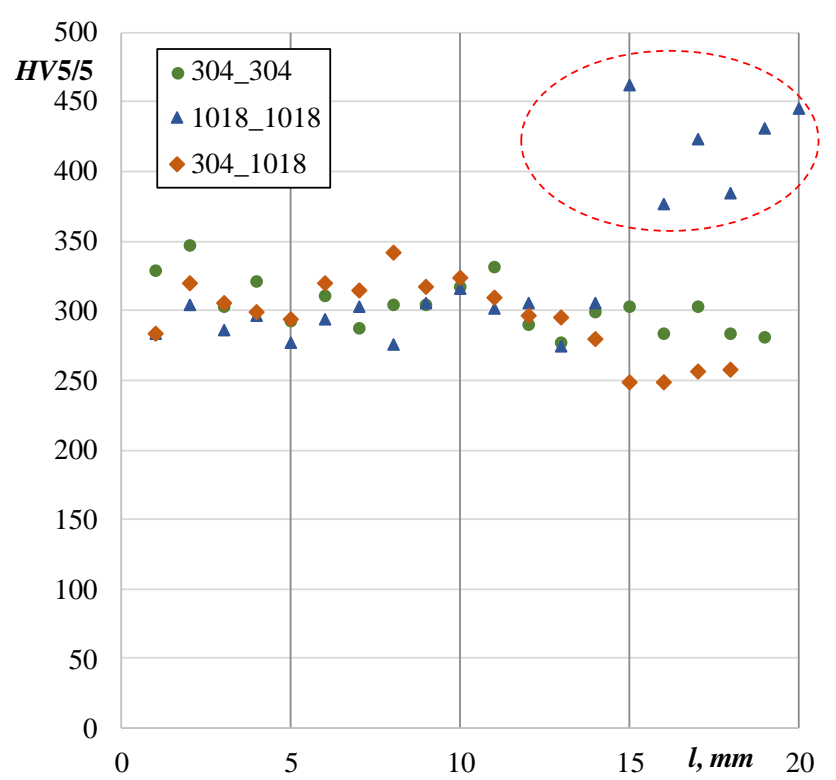

Fig. 8 Hardness along the welded zone of specimens

\section{Finite element analysis}

Finite element analysis (FEA) was performed to check the stress-strain state of the welded specimens and to develop a model for the further parametric analysis. Employing axial symmetry of the specimen and load, the 2D geometry was created, representing a half of the longitudinal section of the specimen (Fig. 2). The butt weld dimensions and a finite element mesh is shown in Fig. 9. Axisymmetric finite element (FE) model was created and solved by ANSYS software. In the FE model, one end of the specimen was fixed and the other was loaded by an increasing displacement, i. e. the specimen was under tension. Large displacement mode was set in the software. The material nonlinearity was defined by isotropic hardening rule and bilinear approximation of the stress-strain curves (Fig. 10).

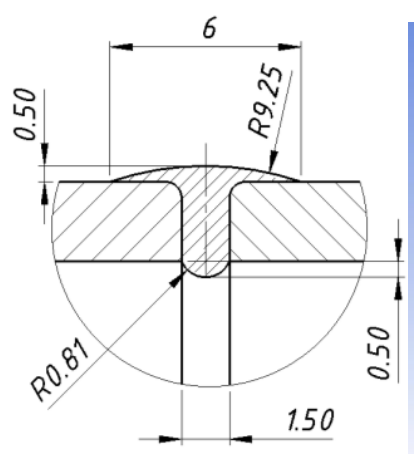

a

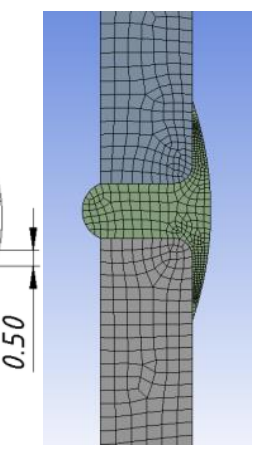

b
Fig. 9 Butt weld dimensions used in modelling (a) and FE mesh (b) of the axisymmetric section

Fig. 11 presents the results of equivalent (Mises) plastic strain for the specimen welded of AISI 304 steel parts with the AISI 308L weld material. The strain here is at the load level when the maximum approaches the elongation strain at the brake of the main material (40\%). The reactionforce at this strain was $44.9 \mathrm{kN}$. This is considered as a maximum force. Similarly, Fig. 12 shows the Mises plastic strain in the specimen welded of steel AISI 304 and 1018 steel with the weld of AISI 316L. The maximum force here was $46.7 \mathrm{kN}$ when the maximum strain was $40 \%$. 


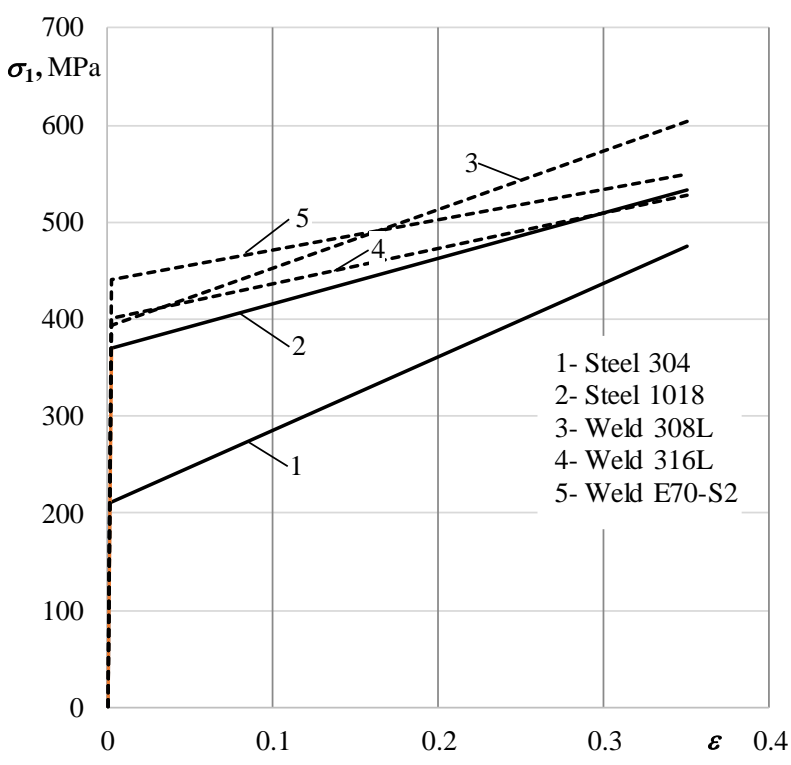

Fig. 10 Bilinear approximation of the stress-strain curves

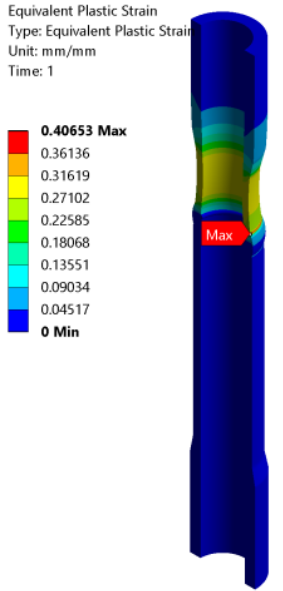

Fig. 12 Mises plastic strain in a welded specimen combined of steel 304 and 1018

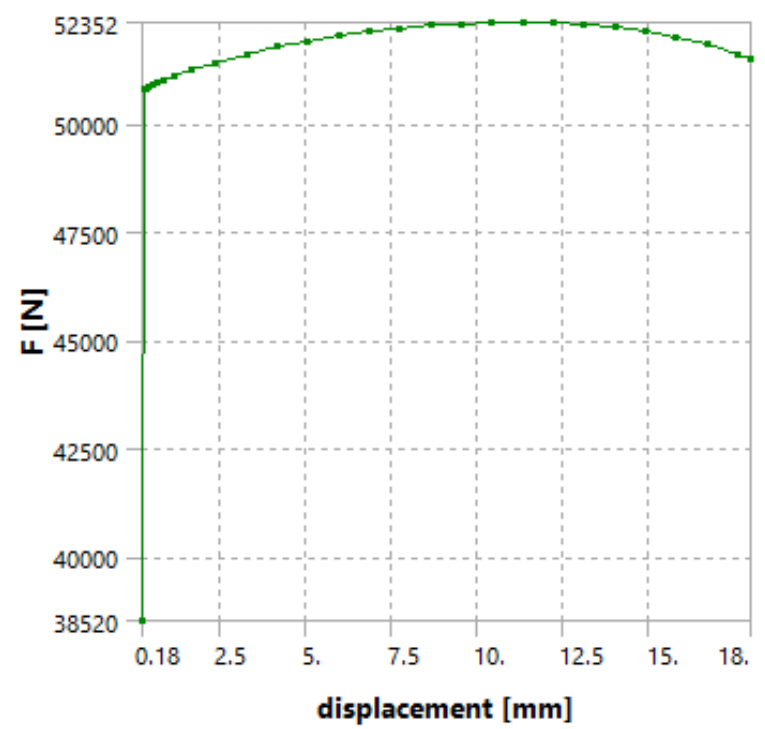

Fig. 13 Reaction force - displacement relation in the model of steel 1018 welded specimen

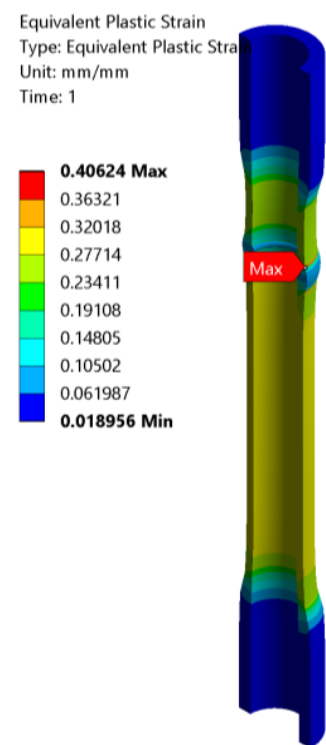

a

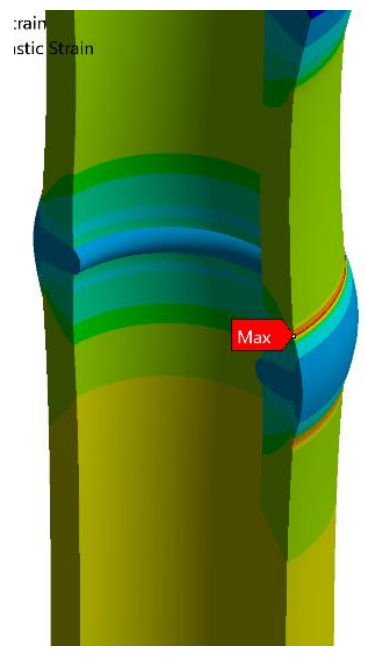

b
Fig. 11 Mises plastic strain in the axisymmetric model of the welded specimen of steel 304 parts: general view (a) and a weld zone (b)

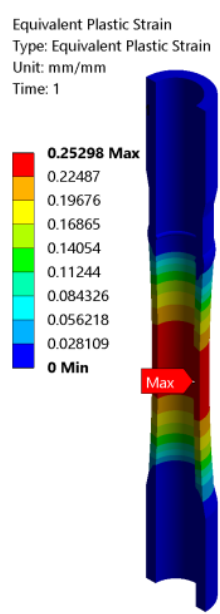

Fig. 14 Mises plastic strain distribution in a welded specimen of steel 1018 under the maximal force $52.4 \mathrm{kN}$

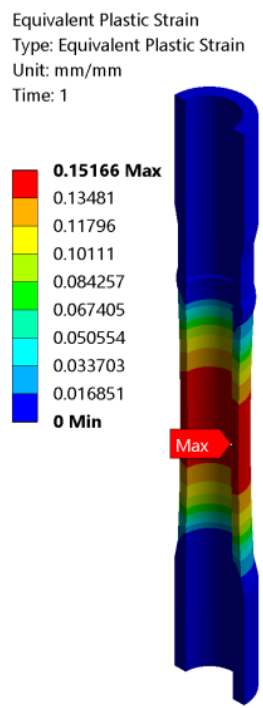

Fig. 15 Mises plastic strain distribution in a welded specimen of steel 1018 under the maximal strain of $15 \%$ 
Fig. 13 shows a relation between a reaction force and displacement in the model of steel 1018 welded specimen. The maximum force $(52.4 \mathrm{kN})$ was reached under the strain of $25 \%$ (Fig. 14). However, this strain is large than the elongation limit of the material (15\%). The maximum force under the strain level of $15 \%$ (Fig. 15) is $52.2 \mathrm{kN}$.

\section{Conclusions and discussion}

The tensile test of the welded specimen, made of stainless steel and welded using 308L filler material, showed that breaking point is at $87.5 \mathrm{kN}$. For the specimens of mild steel welded using E70-S2 filler material it was $87.0 \mathrm{kN}$ and the specimens welded of the combined 304 and 1018 steel with the weld filler of $316 \mathrm{~L}$ steel the breaking point was at $85.0 \mathrm{kN}$ load. These results fit in to a range of $3 \%$ and it demonstrated that there is no significant difference in the strength of the tested cases.

The hardness test allowed to specify the weld zone of the E70-S2 filler for the mild steel specimens, however, for the stainless steel specimens the hardness variation in the weld zone was insignificant.

The finite element analysis gave a maximum load forces $44.9 \mathrm{kN}$ for the stainless steel welded specimen at the elongation limit of the material. Maximum force of $46.7 \mathrm{kN}$ was for the combined specimen and $52.2 \mathrm{kN}$ for the mild steel specimen. These forces are about $40-45 \%$ lower comparing to the experimental test results. This difference can be explained by the approximation of the properties of the materials used in FEA. Because the separate materials were not tested for the mechanical properties, the minimum values were used taken from the references. However, the FE model still can be useful for parametric analysis and corrected having the more accurate data of the material properties.

\section{References}

1. Douthett, J.A. 1995. Designing Stainless Exhaust Systems. Automotive Engineering 103(11): 45-49.

2. Singh, R.; Singh, S. 2017. Additive manufacturing: an overview. Reference module in Materials science and materials engineering. http://doi.org/10.1016/B978-0-12-803581-8.04165-5.

3. Oliver, D.C.; Sephton, M. 2003. External corrosion resistance of steel and ferritic stainless steel exhaust systems, The Journal of the South African Institute of Mining and Metallurgy, p. 93-100.
4. Behzadnasab, M.; Mirabedini, S.M.; Esfandeh, M. 2013. Corrosion protection of steel by epoxy nanocomposite coatings containing various combinations of clay and nanoparticulate zirconia, Corrosion Science 75: 134-141. http://dx.doi.org/10.1016/j.corsci.2013.05.024.

5. Rathod, D.W.; Pandey, S.; Singh, P.K.; Prasad, R. 2015. Experimental analysis of dissimilar metal weld joint: Ferritic to austenitic stainless steel, Materials Science and Engineering 639: 259-268. https://doi.org/10.1016/j.msea.2015.05.011.

6. Smith, D. 1984. Welding Skills and Technology. New York: McGraw-Hill Book Company, 654 p.

7. BS EN ISO 5817: (2007) Welding - Fusion-welded joints in steel, nickel, titanium and their alloys (beam welding excluded) - Quality levels for imperfections.

8. Mechanical properties of stainless steel and mild steel [accessed 20 April, 2017]. Available from Internet: http://www.azom.com/mild steel/stainless steel.

9. Mechanical properties and weld parameters of filler materials [accessed 20 April, 2017]. Available from Internet: http://www.weldwire.net/3081/3161/E70s2.

10. Davis, J. R. 2004. Tensile testing (2nd ed.). ASM International. 283 p.

V. R. Chinnappashanmugam, J. Baskutiene, S. Baskutis, E. Narvydas, K. Vaitasius

\section{THE ANALYSIS OF DISSIMILAR METALS WELD JOINTS}

S u m m a r y

Presented paper deals with the exhaust system parts manufacturing processes. The welded specimens of stainless steel, mild steel and combined stainless-mild steel specimens were made and tensile tests were carried out. Finite element model for the parametric analysis was developed. Obtained results may be useful while selecting the material and manufacturing technology for the exhaust system parts.

Keywords: exhaust manifolds, steel welding, finite element analysis.

Received April 05, 2018

Accepted April 18, 2018 